\title{
Anamorfose de um dia: o tempo da história e o dia 11 de dezembro de 1972
}

\author{
Anamorphosis of One Day: Historical Time and the $11^{\text {th }}$ December, 1972
}

\author{
Daniel Faria \\ krmazov@hotmail.com \\ Professor Adjunto \\ Universidade de Brasília \\ SQN 408, Bloco C, apto 210 \\ 70856030 - Brasília - DF \\ Brasil
}

\section{Resumo}

Neste artigo são apresentadas uma narrativa historiográfica centrada num dia em particular, 11 de dezembro de 1972, e uma breve discussão teórica sobre as relações entre poética, tempo e história. A escolha desse dia se deu a partir da leitura de uma carta escrita por Honestino Guimarães, presidente da UNE na clandestinidade e desaparecido político, a seus familiares. A opção pelo conceito de anamorfose para a categorização deste relato, no lugar de simplesmente "história", deveu-se à percepção de que a estratégia narrativa necessitava de melhor explicitação conceitual. São dois os objetivos principais deste trabalho: em primeiro lugar, apresentar uma experiência de narrativa historiográfica ao leitor, na procura de uma nova perspectiva para se pensar a história contemporânea, em particular a história da ditadura militar no Brasil; em segundo lugar, elaborar algumas questões teóricas a partir dessa experiência, tendo em vista não apenas a experiência em si, mas também suas relações com a escrita da história.

\section{Palavras-chave \\ Poética; Tempo; Historiografia brasileira.}

\begin{abstract}
This article presents a historical narrative of a specific day, December $11^{\text {th }}, 1972$ and a brief theoretical discussion about the relations between poetics, time and history. The date was selected based on the study of a letter written by Honestino Guimarães, then underground president of Brazil's National Students Union (UNE), who suffered forced disappearance during the military dictatorship, to his family. The anamorphosis-concept was chosen for this account due to the perception that the narrative strategy needed a better conceptual approach. This work has two main goals: first, to present an experimental historical narrative to the reader, searching for a new way of thinking about contemporary history, more specifically the history of Brazil's military dictatorship; second, to elaborate some theoretical questions around this experience, bearing in mind not only the experience itself, but also its relations with history writing.
\end{abstract}

\section{Keywords}

Poetics; Time; Brazilian historiography.

Recebido em: 23/7/2014

Aprovado em: 7/10/2014 
Há urubus no telhado e a carne seca é servida. Escorpião encravado na sua própria ferida não escapa, só escapo pela porta da saída.

Torquato Neto. Todo dia é dia $D$.

Após a apresentação da anamorfose do dia 11 de dezembro de 1972, o leitor encontrará algumas considerações teóricas que orientaram a produção deste artigo e outras que surgiram durante a realização do trabalho. Elas giram em torno dos modos de elaboração do tempo pela escrita da história e de alguns temas correlatos, tais como contextualização e poética. Além disso, o artigo contém uma explicação sobre a escolha do conceito de anamorfose para a categorização deste relato, em lugar da opção mais simples que seria a de denominar o que segue "história de um dia". Este texto traduz uma dupla ambição: de um lado, a de que sirva como experimento historiográfico, no sentido de uma tentativa um tanto incomum de que traga questões interessantes para além de seus limites mais imediatos; de outro, a de que seja um relato histórico que se sustente por si mesmo. ${ }^{1}$

\section{Anamorfose de um dia: 11 de dezembro de 1972}

A foto mais conhecida do planeta Terra foi tirada a 10 de dezembro de 1972, por um astronauta da missão Apolo 17. Essa é, também, a última fotografia espacial de nosso planeta resultante da pressão realizada por uma mão humana sobre um aparelho. Se pensarmos em algo que garantiria alguma coerência para o propósito de escrever a anamorfose de um dia, essa imagem do planeta como um todo seria um possível suporte, algo como um contexto. Trata-se, porém, apenas de uma coerência possível e provavelmente ilusória, porque pessoas que vivem no mesmo tempo e lugar (qualquer que seja o recorte cronológico) não necessariamente habitam o mesmo mundo.

No dia seguinte ao dessa fotografia, 11 de dezembro de 1972, os astronautas pousavam na Lua e Honestino Guimarães, então presidente da UNE em clandestinidade, escrevia uma carta para sua mãe, escondido num apartamento no Rio de Janeiro (MONTEIRO 1998, p. 161-162); na madrugada, entre os dias 10 e 11, a banda Pink Floyd apresentava um espetáculo em Lyon. ${ }^{2}$ Cada um desses personagens pode ser imaginado como encapsulado em seu destino, sem nada saber dos outros (provavelmente). É plausível supor que mesmo o vizinho de Honestino não soubesse que ele escrevia aquela carta - nem estivesse ciente de que o jovem que morava ao lado era presidente da UNE e foragido da ditadura. A mãe de Honestino, Maria Rosa, em Brasília, não sabia que seu filho escrevia uma carta que chegaria a ela dias, semanas ou mesmo meses depois. Talvez, cada um dos integrantes de Pink Floyd estivesse numa viagem muito pessoal, intransferível, mergulhado na pulsação de seu instrumento musical, captada por aparelhos especiais, no ritmo das luzes e no clima psicodélico, sobretudo durante a execução de "One of These Days" (viagem talvez interrompida pela única passagem

\footnotetext{
${ }^{1}$ Para a realização deste trabalho foi fundamental minha atuação na Comissão Anísio Teixeira de Memória e Verdade da Universidade de Brasília. Embora seu teor seja estritamente individual, este texto seria impensável sem o trabalho eminentemente coletivo da comissão.

${ }^{2}$ A apresentação pode ser ouvida em: http://www.youtube.com/watch?v=sXeeXRpQYLs.
} 
da música cantada por voz humana: "Um dia desses eu vou te cortar em pequenos pedaços"). ${ }^{3}$

No entanto, quando olhamos a fotografia de nosso planeta, acreditamos nos certificar de que todos eles estavam no mesmo lugar flagrado pelas lentes distantes. Mesmo que a foto, de aparência tão abstrata, pudesse ser até a de um planeta desabitado.

O fotógrafo, ao chegar à Lua, provavelmente não sabia nada sobre o espetáculo de Pink Floyd e certamente nada sabia sobre Honestino. Curiosa visão totalizadora essa. Mas, por outro lado, não é esse o caminho da abstração que possibilita alguma inteligibilidade à história? O fotógrafo, apenas um entre outros, fechado em seu mundo no dia 11 de dezembro de 1972, não se confunde com a fotografia e sua aparente objetividade de olhar neutro e inorgânico. A imagem captada dá a ver, com sua percepção inorgânica, um lugar compartilhado - passado o espaço que separa fotógrafo e planeta.

Mas será mesmo que a imagem mostra algo além de uma figura esférica meio azulada, com manchas que oscilam entre o róseo e o esbranquiçado? Ela apenas sugere, funciona mais como uma alusão de totalidade, não constituindo por si mesma um presente pleno - e se nos lembrarmos do que nos diz Hannah Arendt (2001, p. 169-180) sobre a alienação do mundo como projeção do desejo de um olhar externo à sua mundanidade, o famoso ponto arquimediano de onde o planeta seria observado como um objeto, a imagem pode ser vista como uma metáfora da condição alienada dos habitantes deste mesmo lugar (alienada no sentido mais básico de "cindida", "separada").

No desfecho da carta que escreveu à sua família - e que anos depois se tornou pública ao sair em livro, sendo hoje o mote da anamorfose de um dia -, Honestino citou os conhecidos versos de Drummond: "tenho duas mãos e o sentimento do mundo".

Com os depoimentos e informações disponíveis, podemos imaginar como poderia ser um dia na vida de Honestino em dezembro de 1972 . Em primeiro lugar, ele morava num apartamento com outros militantes da Ação Popular (AP), no Rio de Janeiro. Em segundo lugar, os moradores do apartamento estavam preocupados com a aproximação violenta da repressão, visto que planejavam se mudar dali antes do final do ano. A repressão já se abatia sobre a AP, com raptos e assassinatos. Portanto, havia um clima de tensão no ar - para além da tensão "normal" da vida em clandestinidade.

Honestino costumava dormir pouco, por volta de quatro horas por noite. Praticava ioga, para se preparar para resistir à tortura. E vinha se dedicando a uma elaborada autoanálise - não apenas política, mas emocional, subjetiva. Deste último aspecto sabemos pelo teor da carta, em que Honestino assume a voz de irmão mais velho e se dirige aos seus dois irmãos, dando-lhes conselhos sobre a vida, indicando leituras etc. A carta de 11 de dezembro de 1972 pulsa solidão, saudade da família, mas, ao mesmo tempo, é uma afirmação ética da vida que ele escolheu para si.

\footnotetext{
${ }^{3}$ No original: "One of these days I'm going to cut you into little pieces". Tradução nossa.
} 
Uma das leituras sugeridas por Honestino é Demian (HESSE 1993). Se abrirmos o livro na página 19, leremos:

Os poetas, quando escrevem novelas, costumam proceder como se fossem Deus e pudessem abranger com o olhar toda a história de uma vida humana, compreendendo-a e expondo-a como se o próprio Deus a relatasse, sem nenhum véu, revelando a cada instante sua essência mais íntima. Não posso agir assim, e os próprios poetas não o conseguem.

$* *$

A rigor, porém, foi o seguinte trecho da carta de Honestino que deflagrou o projeto de pensar sobre a anamorfose deste dia em particular:

Tenho pensado bastante em vocês todos. E sinto que gosto muito da família que tenho. Nestas horas me dói profundamente não estar com vocês. Sei que seria muito bom a gente conviver um pouco. Quando há amor e uma vontade de transformação em nós e nas pessoas próximas e se leva isso na prática, não há nada melhor. Quando estive com os manos este ano senti que cada vez tenho maior amizade, carinho, ligação com eles. Me sinto amigo pacas destes dois. E quanto não pagaria para convivermos juntos e interagirmos uns sobre os outros! Vi que os dois estão muito inquietos, não estão acomodados dentro de si. $E$ isso é muito bom. Lembra-me o Torquato Neto (não sei se vocês conhecem): "Não era um anjo barroco/ era um anjo muito louco/ com asas de avião/ que disse: Vai bicho/ desafinar o coro dos contentes". É isso aí. Enquanto não estivermos fazendo coro com os contentes, enquanto sentirmos a cuca quente e o sangue correndo, tá tudo azul. Não seremos mortos vivos dos tipos que o Henfil fala: não seremos os mesquinhos da vida. E vejam, meus caros, que a acomodação que eu tô combatendo é uma bem geral, e não apenas acomodação política. O negócio é cada um descobrir a própria medida dos seus passos. Ninguém tem o direito de se amesquinhar, de virar morto-vivo. Ou ainda, ninguém se transforma em morto-vivo sem deixar de ser vivo, de ser gente, e tudo o mais. Aí virado morto-vivo: contente beato, bobo alegre; aplaudidor dos poderosos, das leis morais que estão aí impostas e impositivas; aí, bem aí. Não sei se vocês estão com consciência disso. E isso é nada mais do que filosofia, rumo, perspectiva de vida. É verdade e verdade é coisa inquieta que mexe com a gente (MONTEIRO 1998, p. 161-162).

Manhã de 11 de dezembro de 1972 (no horário do Rio de Janeiro). Em Houston os responsáveis pela comunicação entre o planeta Terra e a Apolo 17 tentavam contatar os astronautas. Sem resposta. O silêncio, porém, não preocupava: pulsações lentas e ritmadas de corações eram captadas por um aparelho especial - os astronautas dormiam (CORREIO DA MANHÃ 11 dez. 1972).

$* *$

Um telex enviado por adido da embaixada do Brasil no Uruguai chegou ao Estado Maior do Exército:

F conjuntas prenderam Flavia Schilling vg brasileira vg filha de Paulo Schilling et envolvida mln pt ao ser capturada vg tentou resistir vg sendo ferida a tiro no pescoço vg mas estah fora de perigo vg portava pistola 
com vários carregadores et estava sendo procurada desde hah meses pt cel Moacy. ${ }^{4}$

Flávia Schilling, então com 19 anos de idade, foi baleada pela polícia uruguaia a 24 de novembro de 1972. Depois disso, ficaria presa até 1979 na penitenciária de Punta de Rieles, bairro da periferia de Montevidéu. Um dia antes de esse telex chegar ao Brasil, ela escreveu uma carta a seu pai. Por essa carta podemos saber que no dia seguinte, 11 de dezembro, ela ainda se recuperava de uma traqueotomia (porque uma das balas tinha destroçado sua epiglote) e não podia comer. Ela diz que estava "uma magra cadavérica" (SCHILLING 1978, p. 12), que tossia demais e que tinha muita dificuldade de falar. Sentia muito calor devido ao pijama de flanela e acordara cedo, às 6 horas da manhã.

Às 16:37 (horário do Rio de Janeiro), a nave Apolo 17 ocultou-se atrás da Lua, perdendo contato com a Terra (CORREIO DA MANHÃ $11 \mathrm{dez} .1972$, p. 8). A alunissagem ocorreu às 16:55 no lugar correspondente ao que seria o olho da face esquerda da Lua. Às 20:33, Eugene Cernan e Harrison Schmitt passearam de jipe pela superfície lunar.

Na internet, encontramos o depoimento de dois homens sobre um ambiente inóspito, numa paisagem de extrema brancura (CANTON s/d). Eles pensavam estar na parte chilena da Cordilheira dos Andes, mas o avião tinha caído em território argentino.

O texto se refere a Álvaro Mangino e José Inciarte, dois dos 16 sobreviventes do desastre aéreo ocorrido a 13 de outubro de 1972, desastre marcante para a memória coletiva por conta da sobrevivência no ambiente completamente hostil dos Andes ( 4 mil metros de altura, de menos 15 a menos $30^{\circ} \mathrm{C}$ de temperatura) e pelo fato insólito de os sobreviventes terem se alimentado da carne dos mortos. No avião, um bimotor Focker 27 que saíra de Montevidéu rumo a Santiago do Chile, iam 45 pessoas, atletas e familiares, para a disputa de uma partida de rugby. Por conta de possíveis complicações com a crise do governo de Allende, o avião ia com muitos mantimentos - o que foi essencial para a sobrevivência de 16 pessoas (oito pessoas morreriam no acidente, $\mathrm{e}$, até o dia do resgate, mais 21 morreriam).

No dia 11 de dezembro de 1972 os sobreviventes estavam nos Andes havia, praticamente, dois meses. Faltavam, ainda, 12 dias para o resgate (o que, com o perdão da obviedade, eles não tinham condição de prever). Dois meses depois do acidente, o momento mais drástico do choque, das mortes, do sangue nos ferros retorcidos, já era passado. Os sobreviventes tinham aprendido a transformar a neve em água - porque a neve não poderia ser ingerida para matar a sede, por queimar a boca e a garganta. Por outro lado, eles tinham conseguido sintonizar as rádios de Montevidéu e tinham ficado sabendo por elas que as buscas tinham sido canceladas. E já estavam se alimentando dos corpos dos colegas mortos. Por fim, já tinham passado por uma terrível e mortal avalanche.

\footnotetext{
${ }^{4}$ Documento disponível no Arquivo Nacional. Memórias Reveladas, ACE 52546/72.
} 
E foi então, a 11 de dezembro de 1972, quando da morte do último dos sobreviventes antes do resgate e depois de três dias de deliberações e planejamentos, que eles decidiram partir em busca de socorro. Nessa jornada, Roberto Unta e Fernando Dogay acabariam encontrando Sergio Catalán Martínez, um condutor de mulas. Como ele estava na outra margem de um rio, enviaram-Ihe um bilhete com esta mensagem: "Vimos de um avião que caiu na montanha. Somos uruguaios. Há dias que caminhamos. No avião ficaram 14 pessoas feridas. Temos que sair rapidamente porque não temos o que comer e não podemos caminhar."

$$
* *
$$

No dia 11 de dezembro de 1972, Allende foi descansar no balneário de Varadere, perto de Havana, acompanhado por Fidel Castro (JORNAL DO BRASIL 12 dez. 1972, p. 13).

Um certo J. William Back, de Los Angeles, deve ter ficado satisfeito ao ver que sua mensagem tinha sido publicada pela revista Times: "Richard Milhous Nixon é o Homem do Ano para nós - e o resto do mundo!"5 (BACK 11 dez. 1972, tradução nossa).

Ainda nessa mesma revista (TIME MAGAZINE 11 dez. 1972, p. 32) saía uma nota sobre a Guerra do Vietnã. Naquela mesma segunda-feira, Henry Kissinger se encontraria em Paris com Le Duc Tho, o conselheiro especial do Vietnã do Norte nas negociações para a paz. O tom da Time não era de otimismo, porque Nguyen Van Thieu, o presidente do Vietnã do Sul, segundo a revista, não estava satisfeito com os termos do acordo que se desenhava. Apesar disso, segundo a nota da revista, Kissinger teria recebido um apelido, dado pelos sul-vietnamitas em homenagem à sua atitude incansável de pacificador: "aquele que viaja à noite".

Já um leitor crédulo do Jornal do Brasil - e podemos supor que tal tipo de leitor existia nesse passado - começava o dia esperando que o tratado de paz fosse assinado "nas próximas horas", em Paris.

V R S, um aposentado, foi preso na Praça Mauá, Rio de Janeiro, quando vendia uísque nacional em garrafas com rótulos de uísques importados. À polícia ele disse que apenas queria dar um Natal melhorado para a família, que o dinheiro seria usado para comprar castanhas, nozes, doces e brinquedos (JORNAL DO BRASIL 12 dez. 1972, p. 16).

"Vai bicho, desafinar o coro dos contentes": na carta, Honestino não citou o poema/letra de música de Torquato Neto corretamente. Ele saltou alguns versos. Portanto, provavelmente ele tenha citado de memória - o que indica exatamente o oposto do descaso, isto é, como as palavras de Torquato tinham ficado gravadas em sua subjetividade. Existem duas possibilidades, não mutuamente

\footnotetext{
${ }^{5}$ No original: "Richard Milhous Nixon is the Man of the Year for us - and the rest of the world!"
} 
excludentes, para o encontro de Honestino com o texto de Torquato Neto. A primeira é a de que ele tenha escutado o disco de Jards Macalé, lançado em 1972 , em que a letra aparece musicada (na canção "Let's play that"). A segunda é a de que ele tenha lido ao menos uma de duas colunas de autoria de Torquato publicadas no jornal Última Hora.

O teor da carta, recheada de alusões literárias e de uma referência a Henfil (que indica que Honestino acompanhava as publicações mais alternativas, por assim dizer, da imprensa da época), sugere que é provável que ele lesse os artigos de Torquato Neto. A coluna "Let's play that" era bastante conhecida, tanto por sua força intransferível, quanto por ser um guia cultural, com sugestões de filmes, livros e discos.

Teria Honestino lido a coluna que saiu a 16 de dezembro de 1971 (TORQUATO NETO 2004, p. 304-306)? A carta, escrita num estilo despojado e cheio de vitalidade e voltada para uma ética da existência, apresenta ressonâncias que parecem provir desse texto (claro que com a diferença de que Torquato era mais marginal e aristocrático). Nele, Torquato apresentara uma espécie de guia de sobrevivência em tempos sombrios, em aforismos como: "Primeiro passo é tomar conta do espaço". "Não se esqueça de que você está cercado, olhe em volta e dê um rolê. Cuidado com as imitações." "Acredite na realidade e procure as brechas que ela sempre deixa. Leia o jornal, não tenha medo de mim, fique sabendo: drenagem, dragas e tratores pelo pântano. Acredite." "Poesia. Acredite na poesia e viva. E viva ela. Morra por ela se você se liga, mas, por favor, não traia. O poeta que trai sua poesia é um infeliz completo e morto. Resista, criatura." "Eu, pessoalmente, acredito em vampiros. O beijo frio, os dentes quentes, um gosto de mel."

Entre esses aforismos, Torquato incluiu o poema:

Quando eu nasci, um anjo louco, morto, curto, torto veio ler a minha mão. Não era um anjo barroco: era um anjo muito pouco, louco, solto em suas asas de avião. E eis que o anjo me disse, apertando a minha mão entre um sorriso de dentes: vai bicho, desafinar o coro dos contentes.

Ou teria Honestino lido a coluna do dia 19 de janeiro de 1972 (TORQUATO NETO 2004, p. 352-354)? Ela é um pouco mais sombria, tomada pela atmosfera asfixiante do início dos anos 1970, parecendo expressar uma espécie de fim de festa:

Agora não se fala nada

Toda palavra guarda uma cilada

E qualquer gesto é o fim no seu início.

Agora não se fala nada

E tudo é transparente em cada forma

Qualquer palavra é um gesto

E em sua orla

Os pássaros sempre cantam no hospício.

Aqui, o poema citado por Honestino soa mais como um inconformismo que não cede, um hino de resistência; "quase um jogo entre desespero e esperança", 
alguém de sensibilidade muito especial teria dito, e o historiador ouviria a frase como um eco de saudade nascida em poeira vermelha, numa noite de insônia, o coração preso como que numa gaiola.

Nessa coluna, Torquato começa relatando uma conversa com Rogério Duarte em que estão embaralhadas alusões à loucura e à religiosidade: um amplo corredor, pessoas vestidas de branco, podendo ser um rito afro ou uma enfermaria. Era o mesmo Rogério Duarte que, anos depois, traduziria o Bhagavad Gita de uma maneira muito bonita e original. E neste ponto o tempo se embaralha como um novelo, uma rede sem causalidade, mas repleta de ressonâncias: lembremos que Honestino praticava ioga para se preparar para resistir à tortura.

No disco que acompanha a tradução de Rogério Duarte, com textos extraídos do Bhagavad Gita musicados, encontramos a canção "A visão do Yogui sincero", que nos dá uma imagem desse tempo mais sutil e enredado:

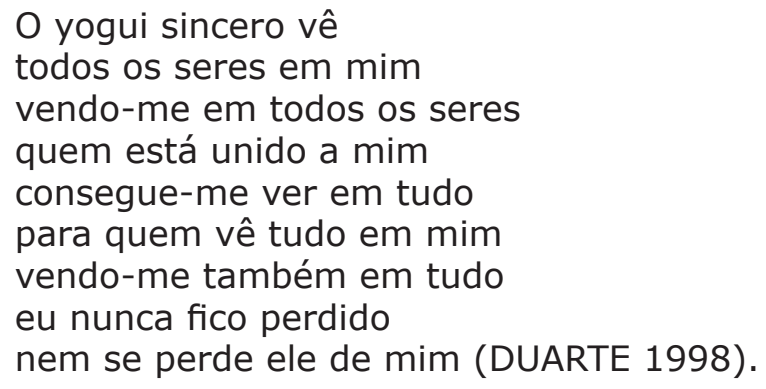

"Ipanema ganha hoje sua primeira ótica realmente pra frente - a Style, que será inaugurada com um movimentado cocktail" (JORNAL DO BRASIL 11 dez. 1972, p. 3).

Será que Honestino sabia que Torquato Neto tinha se suicidado um mês antes do dia 11 de dezembro de 1972?

"A lua está nos dando respostas para as quais ainda nem temos perguntas." A revista Time citava essa frase do geofísico Gerald Wasserburg (TIME MAGAZINE 11 dez. 1972, p. 24). A gigantesca diferença de composição química entre Terra e Lua colocara em xeque a tese de que a Lua seria um pedaço da terra expelido em alguma catástrofe cósmica, num passado remoto. Mas, ao menos, tinha-se uma datação para a origem da Lua, algo em torno de 4 bilhões e 600 milhões de anos, e uma constatação: a Terra e a Lua tinham sofrido um intenso bombardeio de asteroides nos seus primeiros 600 milhões de anos.

Dos inquéritos que os astronautas iniciaram no dia 11 de dezembro de 1972, a revista Time destacava: o estudo da atmosfera lunar; a pesquisa do subsolo da Lua à procura de calor; e, pelo uso de um espectrômetro capaz de captar as mais finas partículas da atmosfera, a captação de ondas sonoras geradas por explosões que os cosmonautas detonariam assim que decolassem da Lua. 
Por outro lado, quando vemos os vídeos quase silenciosos dos astronautas na Lua, saltando lentamente, hasteando a bandeira dos Estados Unidos, aquilo parece abstrato, leve, lento. A leitura de Cosmos, de Carl Sagan, sugere ainda outro tempo para a Lua: em primeiro lugar, como, lá, os ciclos de exposição à luz solar são mais curtos, a temperatura muda mais bruscamente, saltando do extremo frio para o calor. Em segundo lugar, por quase não ter erosão, dada a baixíssima pressão atmosférica, sua paisagem é desenhada por eventos de grande impacto que ocorrem e ficam definitivamente gravados na forma de crateras. Dá-se assim a alternância, numa escala inimaginável de bilhões de anos, entre catástrofes cósmicas e tempos vazios, neutros (SAGAN 2002, p. 88).

Um documento originado no Departamento Regional de Polícia de São Paulo Exterior (DOPS/DEREX) foi registrado pelo Centro de Informações da Aeronáutica (CISA) a 11 de dezembro de 1972. Tratava-se de uma advertência sobre uma certa $G P$ B:

G P B, intitulando-se agente de informações, costuma procurar as autoridades para denunciar possíveis crimes que estariam sendo praticados pelas mais diversas pessoas. Segundo apurações, a epigrafada não é vinculada a nenhum serviço de informações e ainda apresenta sinais de debilidade mental. ${ }^{6}$

$$
* *
$$

Neste mesmo dia, novos generais receberam suas espadas, em festa no Distrito Federal. O general Breno Borges Fortes, chefe do Estado Maior, disse na cerimônia que a missão do momento era a integração cada vez maior entre militares e civis.

Durante o evento, devido ao calor infernal debaixo da tenda no Quartel General do Exército, um dragão da independência desmaiou (JORNAL DO BRASIL 12 dez. 1972, p. 4).

Segundo a revista Time, a viagem à Lua tinha um profundo efeito sobre a subjetividade dos astronautas: eles descobriam a poesia e a introspecção. Isso teria, inclusive, um nome: efeito lunar, o qual designaria o estranhamento em relação às atividades cotidianas anteriores à viagem e uma descoberta da humanidade (TIME MAGAZINE 11 dez. 1972, p. 24).

Jim Irwin, um astronauta de uma viagem anterior à Lua, disse que se tratara de uma experiência religiosa, que ele sentira a presença de Deus naquele ambiente inóspito.

Depois da viagem à Lua, os astronautas não se viam mais como apenas norte-americano, e sim como seres humanos - ao menos era o que você poderia ler, se tivesse comprado a revista Time no dia 11 de dezembro de 1972. E, por isso, muitos se engajavam em atos de generosidade e altruísmo.

O vídeo com os astronautas da Apolo 17 hasteando e saudando a bandeira dos Estados Unidos, disponível na internet, passa, contudo, uma impressão

\footnotetext{
${ }^{6}$ Documento disponível no Arquivo Nacional. Memórias Reveladas, BR AN BSB VAZ 0080179.
} 
ligeiramente diferente: pose para fotografia e comentários irrisórios, algo como um turismo cívico lunar. ${ }^{7}$

Em Nova York, um sacerdote cujo nome não sabemos, numa igreja cujo credo desconhecemos, executou o tango La cumparsita. O dia 11 de dezembro de 1972 era véspera do aniversário de Carlos Gardel (CORREIO DA MANHÃ 11 dez. 1972, p. 9).

Segundo documento enviado do Centro de Informações do Exterior (CIEX) para o CISA, em que eram detalhadas as atividades ditas subversivas acontecidas no Uruguai entre 9 e 21 de dezembro de 1972, nenhuma ação desse tipo acontecera no dia $11 .^{8}$

Um relatório de sindicância, assinado pelo delegado de Polícia adjunto (DOPS - São Paulo) Bél. Edsel Magnotti, foi registrado pelo CISA. O tema era uma greve de fome de alguns presos políticos. O delegado afirmava que o objetivo desse tipo de greve era atingir a Segurança Nacional por meio de guerra psicológica e desmoralização da família brasileira e que, portanto, a continuidade do inquérito apenas serviria para causar comoção. Sugeria, assim, que o inquérito sobre a greve de fome fosse arquivado, mas que ela ficasse registrada no histórico penitenciário dos grevistas.

Entre os nomes citados como testemunhas do inquérito o de Aurea Moretti 20 foi o único a ser circulado com uma caneta (reconhecemos a marca da mão humana pela irregularidade do traço, em contraste com as letras impressas). Segundo um relato de autoria da própria Aurea, ela foi presa em 1969 e passou por violentas torturas, entre as quais se incluía a ameaça constante de estupro coletivo. Não fica claro se essa greve de fome teve alguma relação mais direta com tais torturas. ${ }^{9}$

Quem lesse o Correio da Manhã naquele dia ficaria sabendo que o Papa João VI condenava o aborto e criticava o movimento women 's lib. O Papa dizia simpatizar com as causas do feminismo, mas criticava as ideias "distorcidas" da emancipação feminina e defendia que a mulher devia assumir seu papel de mãe (CORREIO DA MANHÃ 11 dez. 1972, p. 9).

O dia 11 de dezembro de 1972 foi, de certo modo, uma data comemorativa. Os dias em nosso calendário são únicos, irreversíveis; no entanto, as celebrações anuais dão um teor de circularidade ao tempo linear. Uma boa imagem para essa temporalidade seria a de uma espiral. "De certo modo" porque, para esse dia, temos apenas celebrações em potencial, datas que, num outro calendário, em outro dos mundos históricos possíveis, poderiam dar ensejo a festas, rememorações, lamentos ou lutos:

\footnotetext{
7 Vídeo disponível em: http://www.youtube.com/watch?v=zp1tGIXcuTI.

8 Documento disponível no Arquivo Nacional. Memórias Reveladas, BR AN BSB IE 010002.

${ }^{9}$ Documento disponível no Arquivo Nacional. Memórias reveladas, BR AN BSB VAZ 1270062.
} 
Mil seiscentos e onze anos antes do dia 11 de dezembro 1972, Juliano, o Apóstata, tornava-se o último imperador pagão do Império Romano.

Trinta e oito anos antes, Bill Wilson, cofundador dos Alcoólicos Anônimos, tomava seu último drinque.

Se estivesse vivo em 1972, o Papa Leão X estaria comemorando seu quadringentésimo nonagésimo sétimo aniversário.

O Jornal do Brasil anunciava para quarta-feira dia 13 de dezembro a apresentação do disco Água e Vinho, por Egberto Gismonti. Entre as músicas desse disco que hoje é considerado um clássico da música brasileira, uma das mais fortes é "Frederico" (sobre, García Lorca, o poeta assassinado pelas forças da reação, com letra de João Carlos Pádua):

Eram passadas, três horas depois

Das ave-marias

Quando o seu corpo de morte caiu sobre a terra fria

Eram passadas, três horas depois

Das ave-marias

Quando o silêncio das almas desceu sobre Andaluzia

Sim, contaram os homens

Assim, falaram teu nome

Te escuto ainda as palavras

Bailando no firmamento

Eram passadas, três horas depois

Das ave-marias

Quando o seu corpo de morte caiu sobre a terra fria

Eram passadas três horas depois

Das ave-marias

Quando o silêncio das almas desceu sobre Andaluzia (GISMONTI 1972).

Quando comenta Demian, de Herman Hesse, em sua carta, Honestino se refere à passagem que compõe o mito central do livro. Num momento decisivo, Emil, o protagonista, desenha uma ave de rapina saindo de um ovo gigantesco (nas palavras do livro, "uma sombria esfera terrestre", um ovo gigantesco sobre um fundo azul celeste). A ave seria uma encarnação de Abraxas, deus de criação e destruição, abarcando bem e mal, desespero e esperança. Para alguma coisa nova nascer (no caso, o próprio desejo de Emil, que lutava por desabrochar), o mundo velho tinha de ser destruído. Pensando no desenho, em Abraxas, em Demian, Emil concluía:

E nesse ponto abrasou-me de repente como aguda chama a revelação definitiva: todo homem tinha uma "missão", mas ninguém podia escolher a sua, delimitá-la ou administrá-la a seu prazer. Era errôneo querer novos deuses, era completamente errôneo querer dar algo ao mundo. Para o homem consciente, só havia um dever: procurar-se a si mesmo, afirmar-se em si mesmo e seguir sempre adiante o seu próprio caminho, sem se preocupar com o fim a que possa conduzi-lo (HESSE 1993, p. 148). 


\section{Algumas considerações teóricas}

A ideia de escrever este texto surgiu de discussões, aulas e leituras que venho fazendo em torno do tema do tempo na escrita da história. Existe certo consenso acadêmico quanto à tese de que a estratégia narrativa adotada por um historiador corresponde, em grande medida, à interpretação que ele faz sobre o evento, tema ou problema por ele abordado. Evidentemente, em torno desse consenso mínimo formam-se algumas polêmicas, frequentemente mais estridentes do que produtivas. Exemplo disso é a polêmica sobre a natureza do texto histórico, se científica ou literária (quase sempre com pressupostos equivocados sobre o que seria a natureza de um produto do campo das ciências ou da literatura).

Tendo em vista o objetivo deste artigo, o conjunto de respostas oferecidas pela obra de Paul Ricoeur (2007) à polêmica supracitada é suficiente. Tomamos, como ponto de partida, a tese de que, por convenção, um texto histórico participa do amplo espectro dos gêneros narrativos. Admitimos, ainda, que um historiador não é apenas um narrador, uma vez que seu trabalho resulta da combinação de pesquisa com fontes e da adoção de conceitos e teorias. Esses pressupostos mínimos podem ser resumidos com a observação de Anthony Grafton (1998), segundo a qual um texto de história tem, ao menos, duas narrações: a do seu enredo principal e a da auto-história problematizada da elaboração desse enredo (concentrada nas notas de rodapé). Assim, o texto histórico é, convencionalmente, um relato elaborado segundo métodos e

22 conceitos a partir de confrontos com vozes ou discursos exteriores ao próprio texto e, por isso, não é, apenas, uma narrativa.

Por outro lado, é notável constatar, em comparação com a intensidade das polêmicas em torno do tema da narrativa e do tempo e de suas implicações epistêmicas, uma certa timidez quando se trata de experimentos narrativos historiográficos propriamente ditos ("experimentação" no sentido científico ou literário do termo, como se quiser). Com efeito, se existem muitos e por vezes acerbos debates que acenam para um campo em ebulição, a prática historiográfica se mantém, em grande medida, pautada por padrões bem estabelecidos. Se concordarmos com Jacques Rancière (1994) quando afirma que os historiadores enfrentaram seus problemas teóricos poeticamente, essa constatação se torna inquietante. Por "poética" há de se entender aqui não a efusão literária subjetiva e romântica de um gênio e sim a elaboração de uma linguagem, de um regime de signos, de uma trama. De acordo com Rancière, portanto, seria no próprio traçado de sua escrita que o historiador lidaria com seus embaraços teóricos e conceituais. Um exemplo clássico disso é o de Braudel; ele procurou desbravar novas temporalidades e, se o fez em textos teóricos, deu substância e força à sua proposta ao elaborar relatos estruturados segundo tais temporalidades.

Pois bem, partiu-se, aqui, da decisão de se escrever algum tipo de "história de um dia", com um intuito bem aberto e experimental - o que não significa falta de rigor acadêmico. Mas não a história de um dia que fosse um marco histórico consagrado. Porque a opção não foi pautada pela decisão de se mergulhar numa 
data marcante para um período já consolidado como "histórico" e sim pelo desejo de se pensar, na prática, ou seja, poeticamente, em que medida uma distorção do tempo mais habitual para os historiadores poderia produzir uma narrativa histórica interessante. Isso não implica nenhuma pretensão normativa, uma vez que todo discurso sobre "como se deveria escrever a história" esbarra e, em menor escala, ameaça uma das grandes virtudes da historiografia - a sua pluralidade.

É claro que este projeto tem forte inspiração no livro de Gumbrecht sobre o ano de 1926 (GUMBRECHT 1990). Contudo, observe-se, quase a contrapelo, uma vez que, logo no início de seu livro, Gumbrecht afirma que escolheu o ano como medida por se tratar de uma escala temporal razoável, suficiente para se construir um cenário, um mundo habitável, reconhecível. E é mais ou menos evidente que a escolha de um dia, como unidade temporal, cria problemas graves de verossimilhança, no sentido da quase impossibilidade de se construir qualquer coisa que se pareça com um mundo num espaço de tempo tão curto. Digamos o seguinte: exatamente pelo encurtamento temporal, a história de um dia é mais inverossímil do que a história de um ano (o que não desabona o projeto, uma vez que a verossimilhança diz respeito a padrões narrativos e a sua relação com a recepção, ao passo que o conhecimento é, muitas vezes, inverossímil).

Se tanto algo como a história de um dia quanto a história de um ano, quaisquer que sejam as datas escolhidas, são impossíveis no sentido ingênuo de história completa, porque o que o historiador pode compor são dias e anos virtuais, possíveis, em suma, narrados, a história de um dia traz, como resultado paradoxal do encurtamento temporal, uma abertura mais evidente para o ilimitado do tempo vivido frente aos limites do dizível. Isso, sobretudo, porque os historiadores trabalham com constructos temporais que são, ao mesmo tempo em que cronologias, delimitações de um problema ou uma intriga. Quando Gumbrecht se propõe a fazer um livro sobre o ano de 1926, é mais ou menos esperado - e o autor destaca isso - que o ano narrado seja fruto de uma composição e que, portanto, existam elementos, momentos ou situações nesse ano que possam funcionar como marcos ou balizas. Mesmo não optando, propositalmente, por um ano marcante, esse ano pode ser virtualmente construído porque o autor elenca códigos e dispositivos que o organizam como uma espécie de cenário. A história de um dia, pelo contrário, seria uma história fora dos eixos - exceto o caso de esse dia ser um marco consolidado na memória coletiva, no sentido de algo como "um dia que mudou o mundo". Se um dia não é tempo suficiente para mudar nada, sua narração fica, para dizer o mínimo, comprometida - novamente, em termos de padrões de verossimilhança, dos quais, como pesquisadores, não podemos ser escravos.

Por outro lado, no aspecto mais comezinho do trabalho de pesquisa, a história de um dia lança as mesmas dificuldades apontadas por Gumbrecht para seu projeto sobre 1926 e que são praticamente universais quando o assunto é a escrita da história: como selecionar o que entra ou não na narrativa; o confronto com a inviável totalidade, que sempre lança a suspeita de parcialidade por parte do historiador - mesmo no sentido cultural e linguístico; as armadilhas do empirismo, da crença de que os fatos falam por si sós. 
Essa história traz consigo, ainda, um aspecto de jogo aleatório possibilitado pela existência de um novo tipo de arquivo, bem mais desorganizado (ao menos na superfície) e abrangente do que os arquivos tradicionais: trata-se da internet e da possibilidade que ela abre de cruzamentos insuspeitados de informações as mais variadas. Mesmo uma pesquisa básica envolvendo o Google revela esse interessante e pouco explorado manancial: por ser um leitor acrítico, superficial, colado ao significante, o Google devolve informações sobre praticamente qualquer lance de dados que se propuser. Só a título de exemplo, para um contraste, como também pesquisei num arquivo institucional, ali encontrei resistência do atendente, que julgou meu projeto irracional (eu solicitei copias aleatórias de documentos produzidos ou que se referiam ao meu dia de pesquisa). Mas que não se veja nisso qualquer pretensão de estar adequado a um suposto "espírito da época", seja ela denominada de alta modernidade, tardia ou líquida - já foi dito que não se tem aqui qualquer pretensão normativa. Afinal de contas, a história de um dia se comunica bem com um gênero bastante tradicional: a crônica. Sendo assim, uma das virtudes, ou defeitos, deste projeto pode residir exatamente no seu anacronismo.

Pensemos um pouco mais sobre o que significa "um dia" como contexto histórico. Podemos notar, de saída, que um dia é menos fechado em si do que um ano, uma década ou um século, e isso, justamente, por ser mais efêmero. Em outras palavras, um dia funciona mal como unidade estruturante do tempo da narrativa organizada como começo, meio e fim. Um dia é pura abertura no tempo: se é uma unidade do calendário que se conclui em si mesma, simultaneamente não tem começo e fim palpáveis do ponto de vista narrativo - mesmo abstraindo a questão do fuso horário e de se saber em que horas, afinal de contas, um dia acaba de fato. Historicamente, portanto, um dia é mais um ponto de intersecção no tempo do que uma duração que permita que uma história se desenvolva, tal como estamos mais acostumados a concebê-la. Isso quereria dizer que não vale a pena nem mesmo tentar esse exercício, tendo em vista as questões que ele pode lançar? Ou, ainda, que a história de um dia nem mesmo história seria mais? Desconfiança previsível, sobretudo em tempos atuais, em que, depois de tanto se falar em retorno da narrativa, a coisa mais rara de se encontrar entre historiadores é justamente uma narrativa, uma vez que boa parte das pesquisas se volta para problematizações conceituais e para a história da história.

O interessante, portanto, é que a história aqui narrada também serve como laboratório teórico. Prosseguindo na questão do dia e de seu sentido histórico, temos aqui ainda questões sobre a noção e o uso do contexto. O dia escolhido seria um "contexto histórico"? Vivendo no mesmo dia, as pessoas, em sua grande parte, estão no mesmo tempo e não estão ao mesmo tempo. Existem múltiplas formas de relação e modos de as vidas interferirem umas nas outras, mesmo que, num mesmo dia, as pessoas habitem mundos diversos. Mais do que mera seção no calendário, um contexto é um horizonte de racionalidade, faz parte da ordem do possível em que certos acontecimentos se enquadram, na perspectiva do historiador. O contexto é o que torna verossímil a crença compartilhada ou ao menos subentendida de que "o real é racional". O contexto seria algo como 
aquele presente mais que presente equívoco, criticado por Agamben (2009) por ser uma espécie de tempo metafísico que dá sentido aos outros tempos, vividos, experimentados; o presente que, supostamente, explicaria os demais.

Acontece que, num tempo tão próximo ao imediato como um dia, a ordem do possível tende a se esfacelar, no sentido de que não temos campo suficiente, ou mundo narrado, para reconhecermos algum cenário. O muito próximo ofusca como o demasiadamente distante. Sobretudo se quisermos ter um alcance mais amplo do que o de um diário comentado (que seria a história de um dia tal como narrada por fulano). Nesse caso, temos de observar as relações que não se dão no plano consciente dos encontros, no plano verbal das conversas, ou que estejam permeadas por alguma lógica social bem definida. Por exemplo: não existe relação de causa e efeito entre o pouso na Lua e o ato de Honestino escrever sua carta, mas podemos anotar ressonâncias entre os diferentes eventos. Nesse sentido, viver no mesmo dia não deveria ser entendido como se o dia fosse um contexto e sim uma espécie de teia, formada por variados níveis e formas de intercomunicação, ressonâncias - ao menos na forma como o dia 11 de dezembro de 1972 foi tratado, sendo as conjunções mais evidentes substituídas por elipses e deslocamentos.

Mesmo no nível mais básico da pesquisa surgem dificuldades que podem se tornar boas questões. Por exemplo, tendo o jornal como fonte mais óbvia, é preciso ler no mínimo as notícias que saíram no dia estudado e as do dia seguinte; porque é no dia seguinte que um dia passa a contar como "história" ou, ao menos, como memória. É a partir do dia seguinte que as histórias de um dia passam a fazer parte do mundo vivido em comum, porque são relatadas e, por assim dizer, consolidam-se como fatos. Durante o próprio dia, o tempo é vivido nesse imperceptível e finíssimo fluir chamado presente. Sendo assim, estudar um dia é quase como observar num microscópio alguns dos temas mais recorrentes em discussões teóricas e metodológicas da história, como o da relação entre o vivido, o experimento e o lembrado; a memória e o instante - além da já comentada clivagem entre padrões de verossimilhança e conhecimento histórico.

Nova dificuldade: como um historiador não é um romancista, não podemos recorrer aos artifícios do fluxo de consciência ou da onisciência narrativa para conferir densidade ao texto. Se, ao contrário de Joyce em Ulisses, por exemplo, não é possível se adotar a estratégia de acompanhar as minúcias de um dia por meio das sensações e ideias de uma pessoa qualquer, o que se tem, ao final da pesquisa, é um conjunto desconjuntado de acontecimentos, fatos, dados mais ou menos relevantes e mais ou menos interligados entre si; momentos entrelaçados e ao mesmo tempo isolados, sem hierarquia de sentido, uma vez que não sedimentados pela memória ou pela historiografia como um período, uma época. Essa é mais uma característica que complica o propósito narrativo no aspecto do começo e do fim da trama. Porque é a continuidade que faz de um conjunto de eventos um mundo histórico reconhecível. Sendo assim, ao se reduzir a escala do tempo para um dia, é-se quase obrigado a pensar em vários mundos conectados entre si, às vezes de um modo sutil. 
Julio Cortázar tem um livro com um título bem gracioso e que pode dar uma orientação ao propósito da escrita da história de um dia: $A$ volta ao dia em 80 mundos. Isso não significa que se trate aqui de um artifício visando a qualquer viagem no tempo. Em contraste com o livro de Gumbrecht e outras teses similares, não se parte da tese de que vivemos numa era presentista, ou num momento em que a experiência social do tempo foi espacializada ou liquidada de qualquer forma. A leitura de livro de Peter Pal Pelbart (1998) sugere uma crítica pertinente a esse tipo de tese que, paradoxalmente, diagnostica um todo temporal, chamando-o de qualquer variante da modernidade: o problema é que o tempo não é homogêneo. Assim, a imagem do passado como presente a ser revisitado implica uma operação que tende a anular a diferença, a pluralidade dos tempos. Existe algo de irreversível no tempo que passa, que passou; embora, é claro, isso esteja longe de ser tudo o que se pode falar sobre o tempo, uma vez que o passado também retorna, seja como memória, trauma ou repetição, e assim segue operando na atualidade. Mas, enfim, não há nada de familiar nisso tudo, e o passado não é um mero presente passado.

Tudo parecia tão simples, no começo, mas eis que a redução da história para um dia em nada diminui a complexidade do entrelaçamento dos diferentes ritmos e temporalidades sociais, culturais, políticas, subjetivas e o trabalho historiográfico, porque o próprio dia tem em si essa pluralidade de tempos que apontamos. Nesse aspecto, um dia pode ser como um século, ou mesmo como algo mais, como aquilo que Pomian (1993) conceitua como "arquitetura temporal", 26 camadas e camadas de diferentes tempos sobrepostos, complementares, tensos, dando forma ao imenso edifício da modernidade. O tempo do calendário, o tempo social das comunicações, o tempo da política e das guerras, das relações pessoais etc., sobrepostos, justapostos, entrecruzados formando a arquitetura de uma catedral barroca, na melhor das hipóteses em termos estéticos, ou até mesmo uma Torre de Babel e, quem sabe, a casa muito engraçada da canção infantil de Vinícius de Moraes.

Foi devido a essa complexidade temporal que se optou, por fim, pelo conceito de anamorfose. Anamorfose e não apenas a história de um dia, porque provavelmente o leitor poderia pensar que se trataria de um projeto ingênuo de completude narrativa - como se fosse suficiente escandir um dia em horas e anotar acontecimentos, numa espécie de cronologia minimalista. Anamorfose porque essa história, não sendo "literatura", é, como todas as outras, uma mescla de pesquisa e elaboração poética.

A anamorfose, como técnica de produção de artefatos culturais (CORREIA 1985 , p. 192-193) corresponde a um conjunto de operações, a princípio das artes plásticas, que consistem em arruinar a perspectiva, deslocando as formas para além de si mesmas, distorcendo-as, alongando-as, encurtando-as. É como se um desenho fosse feito a partir da posição de um espectador numa situação extravagante qualquer, e não da perspectiva com a qual nos habituamos desde a Renascença. Uma torre desenhada segundo a perspectiva de alguém deitado a seu pé, em vez de por um observador numa posição dita razoável, seria um exemplo. Baltrusaits observa que a anamorfose, com as imagens de corpos 
distorcidos, não é mera diversão: há nela uma teoria sobre a realidade factícia, uma poética da abstração (BALTRUSAITS 1977, p. 61-70). Trazendo o tema para o campo da escrita, Natalia Correia aduz que existe uma perspectiva mental habitual que se confunde, por vezes, com a perspectiva natural ou mesmo com a própria realidade, quando se trata apenas de bom senso, verossimilhança. A atenção intensiva sobre um detalhe, a ponto de agigantá-lo, não implica perda da realidade ou de objetividade, mas pode ser a descoberta de uma nova perspectiva. Obtém-se, ainda, uma desejável conquista ética com a opção pela anamorfose: trata-se da negação de todo sistema que pretenda ter um valor absoluto.

Última observação: como foi observado na própria anamorfose, foi a leitura de uma carta de Honestino Guimarães, que viria a ser assassinado por agentes da ditadura em 1973, o que pautou a escolha do dia 11 de dezembro de 1972. Com isso, o dia acabou ganhando uma atmosfera, um tema. Trata-se da solidão, da procura pelo outro, da comunicação. E se falamos em alienação e violência, sem dúvida é toda uma atmosfera da vida contemporânea que se elabora nesta anamorfose. É como se a perspectiva escolhida para a realização deste trabalho fosse próxima daquela a partir da qual Honestino poderia observar os acontecimentos do dia. Ao mesmo tempo, porém, essa escolha acaba resvalando na ideia de que, num mesmo dia, pessoas vivem em mundos diferentes. A imagem fotográfica do planeta, em seu elevado grau de abstração, sugere uma totalidade ausente, uma coleção de fragmentos. De alguma forma, esses diferentes mundos vivenciados num dia estão no mesmo mundo, ao menos quando passam a ser objeto de narração. Quanto mais nos aproximamos dos mundos vividos, porém, mais nos aproximamos da dor, que nos leva a um outro tempo, não o cronológico, e sim o tempo ontológico. E então a vida alienada adquire densidade existencial, porque ela é isolamento e dor, e luta contra o isolamento e a dor. Sobre esse tempo, em seu livro escrito na prisão, Antonio Negri diz que:

A concretude do tempo é declarada de maneira implacável pela dor, a sua sólida realidade é tão mais verdadeira, quanto mais é determinante o laço entre o tempo e a morte. Mas não é só isso. A morte é tão intrínseca ao ser, a todos os seres e a todo o ser, que ela estabelece a medida comum, a razão interna de constituição ordenada do mundo. Nesse percurso que vai da dor à morte constitui-se a possibilidade de uma ordem que não seja medida transcendente, mas atividade interior de ordenamento. Contudo, isso não basta. Se a universalidade da morte e do sofrimento nos faz reconhecer o tempo como manifestação do ser e realidade comum de nossa existência, ao contrário do que queriam os idealistas de todos os tipos, esse reconhecimento certamente não afasta a dor e a morte - ele funda antes a necessidade, a paixão de eliminá-los. O ser-para-a-morte é a base da vontade de potência. O ser na dor é o impulso para a ressurreição da vida, é a profecia da ressurreição dos corpos (NEGRI 2007, p. 132-134).

No final das contas, o dia escolhido para essa anamorfose não foi aleatório. Mais importante do que quaisquer reflexões derivadas do experimento, a história que abre esse artigo é a de um dia numa vida aberta para a dor e, portanto, para a redenção. O relato, portanto, não é mero pretexto para as teorizações que o seguem; a afirmação inversa está mais próxima da verdade. 


\section{Referências bibliográficas}

AGAMBEN, Giorgio. O que é o contemporâneo e outros ensaios. Traduzido por Vinícius Nicastro Honesko. São Paulo: Argos, 2009.

ARENDT, Hannah. A condição humana. Rio de Janeiro: Forense Universitária, 2001.

BACK, William. Richard Milhous Nixon is the Man of the Year for us - and the rest of the world. Times Magazine, New York, 11 dez. 1972. Letters.

BALTRUSAITS, Jurgis. Anamorphic art. New York: Harry N. Abrams, 1977.

CANTON, Olides. Os Sobreviventes dos Andes - Texto completo. Disponível em: http://www.deolhoseouvidos.com.br/artigos/sobreviventes.htm. Acesso em: 17 jul. 2014.

CORREIA, Natalia. As anamorfoses. In: HELDER, Herberto. Edoi Lelia Doura. Antologia das vozes comunicantes da poesia moderna portuguesa. Lisoba: Assírio e Alvim, 1985, p. 192-193.

CORREIO DA MANHÃ. Apolo hoje em órbita da Lua. Correio da Manhã, Rio de Janeiro, 11 dez. 1972. Capa, p. 1.

Apolo 17 entra hoje em órbita lunar. Correio da Manhã, Rio de Janeiro, 11 dez. 1972. $1^{\circ}$ Caderno, p. 8.

. Carlos Gardel. Correio da Manhã, Rio de Janeiro, 11 dez. 1972. $1^{\circ}$ Caderno, p. 9.

Paulo VI condena o aborto. Correio da Manhã, Rio de Janeiro, 11 dez. 1972. $1^{\circ}$ Caderno, p. 9.

DUARTE, Rogério. Canções do divino mestre (CD). Companhia das Letras: São Paulo, 1998.

HESSE, Herman. Demian. Rio de Janeiro: Record, 1993 [1925].

GISMONTI, Egberto. Água e vinho (CD). EMI/Odeon, 1972.

GRAFTON, Anthony. As origens trágicas da erudição. Pequeno tratado sobre as notas de rodapé. Campinas: Papirus, 1998.

GUMBRECHT, Hans Ulrich. Em 1926. Vivendo no limite do tempo. São Paulo: Record, 1990.

JORNAL DO BRASIL. Allende descansa em balneário em Cuba. Jornal do Brasil, Rio de Janeiro, 12 dez. 1972. $1^{\circ}$ Caderno, p. 13.

. Novos generais recebem espadas em festa no DF. Jornal do Brasil, Rio de Janeiro, 12 dez. 1972. 10 Caderno, p. 4.

. Ipanema ganha hoje sua primeira ótica pra frente. Jornal do Brasil, Rio de Janeiro, 11 dez. 1972. Caderno B, p. 3.

- Vigarista é detido com uísque falso. Jornal do Brasil, Rio de Janeiro, 12 dez. 1972. $1^{\circ}$ Caderno, p. 16. 
MONTEIRO, Maria Rosa Leite. Honestino. O bom da amizade é a não cobrança. Brasília: Da Anta Casa Editora, 1998.

NEGRI, Antonio. Jó. A força do escravo. Rio de Janeiro/São Paulo: Record, 2007.

PELBART, Peter Pal. O tempo não reconciliado. Imagens de tempo em Deleuze. São Paulo: Perspectiva, 1998.

POMIAN, Kryzstof. Tempo/temporalidade. Traduzido por Maria Bragança. Lisboa: Imprensa Nacional/Casa da Moeda, 1993 (Enciclopédia Einaudi, v. 29).

RANCIÈRE, Jacques. Os nomes da história. Um ensaio de poética do saber. Traduzido por Eduardo Guimarães e Eni Puccineli Orlandi. São Paulo: EDUC/Pontes, 1994.

RICOUER, Paul. A memória, a história, o esquecimento. Campinas: EdUnicamp, 2007.

SAGAN, Carl. Cosmos. New York: Random House, 2002.

SCHILLING, Flávia. Querida família. Porto Alegre: CooJornal, 1978.

TIME MAGAZINE. The War: Paris round 3. Ready to wrap up the peace. Time Magazine, v. 100, n. 24, p. 32, 11 dez. 1972.

. Space, Lunar Science: Light amid the heat. Time Magazine, v. 100, n. 24, p. 24, 11 dez. 1972.

TORQUATO NETO. Literato cantábile. In: PIRES, Paulo Roberto. Torquatália. Geleia geral. Rio de Janeiro: Rocco, 2004, p. 304-306. . Let's play that. In: PIRES, Paulo Roberto. Torquatália. Geleia geral. Rio de Janeiro: Rocco, 2004, p. 352-354. 